\begin{tabular}{|c|c|c|}
\hline Case Reports in & \multicolumn{2}{|c|}{ Case Rep Gastroenterol 2020;14:63-69 } \\
\hline Gastroenterology & $\begin{array}{l}\text { DOI: 10.1159/000505774 } \\
\text { Published online: February 5, } 2020\end{array}$ & $\begin{array}{l}\text { (c) } 2020 \text { The Author(s) } \\
\text { Published by S. Karger AG, Basel } \\
\text { www.karger.com/crg }\end{array}$ \\
\hline & $\begin{array}{l}\text { This article is licensed under the } \\
\text { International License (CC BY-NC) } \\
\text { Usage and distribution for commerc }\end{array}$ & $\begin{array}{l}\text { nons Attribution-NonCommercial } 4.0 \\
\text { ger.com/Services/OpenAccessLicense). } \\
\text { uires written permission. }\end{array}$ \\
\hline
\end{tabular}

\title{
Perforation of the Small Intestine after Introduction of Lenvatinib in a Patient with Advanced Hepatocellular Carcinoma
}

\author{
Naomi Suzukia, b Kazuto Tajiri ${ }^{a} \quad$ Yuka Futsukaichi $^{a} \quad$ Shinichi Tanaka ${ }^{c}$ \\ Aiko Murayama $^{\mathrm{a}}$ Toshiki Entani $^{\mathrm{a}}$ Saito Kobayashi ${ }^{\mathrm{a}}$ Kosuke Takahashi ${ }^{\mathrm{a}}$ \\ Tsutomu Fujii $^{d}$ Johji Imura ${ }^{c}$ Ichiro Yasuda ${ }^{a}$ \\ aDepartment of Gastroenterology, Toyama University Hospital, Toyama, Japan; \\ ${ }^{b}$ Graduate Education and Clinical Training Center, Toyama University Hospital, \\ Toyama, Japan; 'Diagnostic Pathology, Faculty of Medicine, University of Toyama, \\ Toyama, Japan; dThe Second Department of Surgery, Toyama University Hospital, \\ Toyama, Japan
}

\section{Keywords}

Advanced hepatocellular carcinoma $\cdot$ Lenvatinib $\cdot$ Vascular endothelial growth factor

\begin{abstract}
Lenvatinib is a first-line standard treatment for advanced hepatocellular carcinoma $(\mathrm{HCC})$ with better anti-tumor effects than sorafenib, as shown by greater inhibition of the kinases of fibroblast growth factor receptor and vascular endothelial growth factor (VEGF) receptor. This report describes a patient with advanced HCC who experienced perforation of the small intestine 1 month after starting the treatment with lenvatinib. This patient likely had partial necrosis of a metastasis to the small intestine before starting lenvatinib treatment, with subsequent ischemic changes leading to perforation of the small intestine. Although metastasis of HCC to the small intestine is rare, patients with these metastases should be regarded as being at risk for perforation during lenvatinib treatment.

(C) 2020 The Author(s)

Published by S. Karger AG, Basel
\end{abstract}




\section{Case Reports in Gastroenterology}

Case Rep Gastroenterol 2020;14:63-69 DOI: $10.1159 / 000505774$

(c) 2020

www.karger.com/crg

Suzuki et al.: Perforation of the Small Intestine after Introduction of Lenvatinib in a Patient with Advanced Hepatocellular Carcinoma

\section{Introduction}

Hepatocellular carcinoma (HCC) is a highly prevalent disease and is responsible for 800,000 deaths per year worldwide [1]. Most patients are diagnosed with advanced-stage disease, resulting in poor prognosis [2]. The introduction of tyrosine kinase inhibitors (TKI) such as sorafenib and lenvatinib as first-line systemic treatments for unresectable HCC has improved the median overall survival (OS). In the REFLECT trial, lenvatinib showed noninferiority to sorafenib, with a median OS of 13.6 versus 12.3 months (hazard ratio [HR] 0.92; 95\% confidence interval [CI]: 0.79-1.06) [3]. In that trial, lenvatinib showed better anti-tumor effects than sorafenib, as revealed by their objective response rates $(24.1$ vs. $9.2 \%$, odds ratio 3.13 ; 95\% CI 2.15-4.56) and median progression-free survival (7.4 vs. 3.7 months, hazard ratio 0.66 ; $95 \% \mathrm{CI} 0.57-0.77$ ). The difference in the anti-tumor effects of lenvatinib and sorafenib has been associated with their ability to inhibit the activity of certain tyrosine kinase receptors. Lenvatinib targets kinases such as vascular endothelial growth factor receptors (VEGFR) 1-3, fibroblast growth factor receptors (FGFR) 1-4, platelet-derived growth factor$\alpha$, RET, and KIT, with FGFR4 inhibition being regarded as important in preventing aggressive growth or progression to a higher grade of HCC malignancy [4].

All TKIs, however, are associated with a range of adverse events (AEs), which can have a negative effect on patient prognosis and quality of life. The management of AEs influences the adherence of patients to treatment as well as their prognosis. In the REFLECT trial, lenvatinib had severe AEs in $1 \%$ of the patients, with 1 patient each experiencing tumor hemorrhage, ischemic stroke, respiratory failure, and sudden death [3]. Although gastrointestinal (GI) perforations have been reported in few advanced HCC patients during lenvatinib treatment, a patient with thyroid cancer who experienced GI perforation due to lenvatinib has been described [5].

The present study describes a patient with advanced HCC and a metastasis to the small intestine who experienced perforation of the small intestine after starting treatment with lenvatinib. This study also discusses the mechanism underlying this complication.

\section{Case Presentation}

A 75-year-old Japanese male was diagnosed with advanced HCC $12 \mathrm{~cm}$ in diameter and underwent right hepatectomy combined with right diaphragm resection. Histological evaluation of the resected liver showed a moderately differentiated HCC with areas of poor differentiation. He had no history of viral hepatitis, but had been diagnosed with alcoholic liver injury. His body weight was $67 \mathrm{~kg}$, and he had been previously diagnosed with hypertension and has since been treated with amlodipine $5 \mathrm{mg}$. Eight months after the operation, he was diagnosed with recurrent HCC $20 \mathrm{~mm}$ in diameter in the remnant left lobe for which he underwent curative radiofrequency ablation. Three months after radiofrequency ablation, he again experienced a recurrence of HCC, with tumors in the residual right diaphragm and caudal lobe, a tumor thrombus extending into the inferior vena cava, and lung metastasis (Fig. 1a, b). The recurrent HCC was deemed unresectable, but his liver function was well preserved (performance status 0 ), and his general condition was good, despite having anemia (hemoglobin 7.7 $\mathrm{g} / \mathrm{dL}$ ). Blood tests showed that his albumin concentration was $3.0 \mathrm{~g} / \mathrm{dL}$, alanine aminotransferase concentration was $19 \mathrm{IU} / \mathrm{L}$, total bilirubin concentration was $0.4 \mathrm{mg} / \mathrm{dL}$, white blood cell count was $8,270 / \mu \mathrm{L}$, red blood cell count was $266 \times 10^{4} / \mu \mathrm{L}$, platelet count was $21.0 \times$ $10^{4} / \mu \mathrm{L}$, prothrombin activity was $98 \%$, alpha-fetoprotein concentration was $2.2 \mathrm{ng} / \mathrm{mL}$, des- 


\section{Case Reports in Gastroenterology}

Case Rep Gastroenterol 2020;14:63-69

DOI: $10.1159 / 000505774$

(c) 20201

www.karger.com/crg

Suzuki et al.: Perforation of the Small Intestine after Introduction of Lenvatinib in a Patient with Advanced Hepatocellular Carcinoma

$\gamma$-carboxy prothrombin concentration was $808 \mathrm{AU} / \mathrm{L}$, and his Child-Pugh score was 6 points (grade A). After obtaining written informed consent, this patient was started on lenvatinib 12 $\mathrm{mg} /$ day. During the next 4 weeks, he experienced grade 2 hypertension and fatigue, for which he was treated with amlodipine $10 \mathrm{mg} /$ day, candesartan cilexetil $12 \mathrm{mg} /$ day, and dexamethasone $1 \mathrm{mg} /$ day. One month after starting lenvatinib, he experienced a sudden onset of abdominal pain. Computed tomography (CT) showed a perforation of the small intestine (Fig. 1c), for which he underwent immediate surgery. Intraoperative examination showed a perforation of the small intestine $40 \mathrm{~cm}$ from the Treitz ligament, with a palpable nodule around the perforation point. His small intestine was partially resected. Retrospective examination of CT results at lenvatinib initiation showed swelling of the small intestine, probably due to HCC metastasis to this organ (Fig. 1d).

Macroscopic examination of the resected small intestine showed a perforation in a protruding lesion with limited necrosis (Fig. 2a). Histopathologic analysis showed a poorly differentiated HCC that had invaded the entire intestinal wall (Fig. 2b, c), whereas the serous side of the membrane was relatively well preserved (Fig. 2d), indicating a hematogenous, rather than a disseminated, metastasis of HCC. The site of perforation was within a necrotic area of the metastatic tumor (Fig. 2e). The border between the necrotic tissue and viable tumor tissue was relatively distinct (Fig. 2e). The necrotic tissue was surrounded by dilated tumor vessels, which were congested with pooled red blood cells due to clot formation (Fig. 2f). Lymphocyte infiltration was also found around the tumor vessels surrounding the necrotic tissue (Fig. 2f). The necrotic tumor contained tumor vessels with fibrin thrombi (Fig. 2g), suggesting that necrosis involved ischemia due to thrombotic changes in tumor vessels.

The patient was discharged 1 month after surgery, in good general condition and with well-preserved liver function. Two months after the operation, following careful GI evaluation including upper and lower endoscopy, capsule endoscopy, positron emission tomography, and CT examination, he was restarted on lenvatinib. His serum des- $\gamma$-carboxy prothrombin concentration, which was 9,769 AU/L before starting lenvatinib, decreased to 4,849 AU/L after starting lenvatinib.

\section{Discussion}

Lenvatinib is a multi-TKI that was approved in 2018 as a first-line systemic treatment for advanced HCC [3]. It is characterized by strong inhibition of FGFR4 and VEGFR1-3 [6]. Cancer cells, including those in HCC, proliferate and disseminate by forming new tumor vessels through the process of angiogenesis, with VEGF being an essential angiogenic factor [7]. Inhibition of VEGF receptors in various tissues for 1-3 weeks was found to induce significant regression of capillary beds, with a reported reduction rate of $46 \%$ in villi of the small intestine [8], suggesting that VEGFR inhibitors may be harmful to the small intestine. In clinical settings, thromboembolism is an AE of VEGF inhibitors, with an incidence of 5-12\% in colorectal cancer patients treated with the VEGF inhibitor bevacizumab [9]. VEGF inhibition is also thought to play an important role in immunological anti-tumor effects, as bevacizumab induces increases the numbers of dendritic cells and CD8 T cells, while reducing the number of regulatory T cells [10]. In addition, treatment of tumor tissue with FGFR inhibitors has been reported to reduce populations of myeloid-derived suppressor cells, one of the components of the tumor microenvironment [11]. Thus, inhibition of VEGF or FGF signaling has anti-tumor effects, due not only to their antiangiogenic effects but also to immunemodulatory mechanisms. Pathological examination of the present patient showed partial necrosis, along with 
thrombotic tumor vessels and lymphocyte infiltration, which may have been induced by the anti-tumor effects of lenvatinib.

Perforation of the GI tract is a rare $\mathrm{AE}$ of lenvatinib but may be a lethal consequence of antiangiogenic therapies. Rates of GI perforation have been reported to be $1.3 \%$ in patients treated with VEGFR-TKIs [12]. Because lenvatinib has been used to treat advanced HCC patients only since 2018, there have been no reports of GI perforation due to lenvatinib in patients with advanced HCC. However, lenvatinib-associated GI perforation has been reported in a patient with anaplastic thyroid cancer, with the rapid tumor shrinkage effect considered responsible for GI perforation [5]. Other common AEs of lenvatinib, such as hypertension, proteinuria, diarrhea, and fatigue, usually occur within 2 months after initiating therapy [13]. The magnitude of tumor shrinkage is highest in the first 2 months [14], with the highest incidence of AEs occurring during the same period. Our patient experienced GI perforation 1 month after starting lenvatinib, indicating that the clinical course of patients treated with lenvatinib should be carefully monitored.

HCC is a highly invasive tumor that metastasizes to the lungs, regional lymph nodes, adrenal glands, and bones. However, HCC metastasis to the GI tract is uncommon (2\%), and metastasis to the small intestine is rare [15]. HCC patients with metastasis to the GI tract have a poor prognosis, with a median OS of 1 month (range 2 weeks-4 months) [15]. In this patient, metastasis to the small intestine was not detected before he was started on lenvatinib. Capsule endoscopy or double-balloon enteroscopy is recommended for the detection of lesions in the small intestine. Although it is difficult to screen the entire GI tract of all advanced HCC patients before TKI introduction, patients with iron deficiency anemia of unknown origin should be monitored.

\section{Conclusion}

This report is the first to describe a GI perforation due to the introduction of lenvatinib in a patient with advanced HCC. Although the strong antiangiogenic effects of lenvatinib make this agent useful for the control of advanced HCC, it is important to monitor patients for specific AEs.

\section{Statement of Ethics}

Written informed consent for publication was obtained from the patient.

\section{Disclosure Statement}

The authors declare that they have no conflicts of interest to disclose.

\section{Funding Sources}

There were no funding sources. 


\section{Case Reports in Gastroenterology}

\begin{tabular}{l|l}
\hline DOI: 10.1159/000505774 & @ 2020 The Author(s). Published by S. Karger AG, Basel
\end{tabular}
www.karger.com/crg

Suzuki et al: Perforation of the Small Intestine after Introduction of Lenvatinib in a Patient with Advanced Hepatocellular Carcinoma

\section{Author Contributions}

Naomi Suzuki and Kazuto Tajiri wrote this paper, and all authors contributed to the patient's medical treatment.

\section{References}

1 Akinyemiju T, Abera S, Ahmed M, Alam N, Alemayohu MA, Allen C, et al.; Global Burden of Disease Liver Cancer Collaboration. The Burden of Primary Liver Cancer and Underlying Etiologies From 1990 to 2015 at the Global, Regional, and National Level: Results From the Global Burden of Disease Study 2015. JAMA Oncol. 2017 Dec;3(12):1683-91.

2 Forner A, Llovet JM, Bruix J. Hepatocellular carcinoma. Lancet. 2012 Mar;379(9822):1245-55

3 Kudo M, Finn RS, Qin S, Han KH, Ikeda K, Piscaglia F, et al. Lenvatinib versus sorafenib in first-line treatment of patients with unresectable hepatocellular carcinoma: a randomised phase 3 non-inferiority trial. Lancet. 2018 Mar;391(10126):1163-73.

4 Kudo M. Targeted and immune therapies for hepatocellular carcinoma: predictions for 2019 and beyond. World J Gastroenterol. 2019 Feb;25(7):789-807.

5 Date E, Okamoto K, Fumita S, Kaneda H. Gastrointestinal perforation related to lenvatinib, an anti-angiogenic inhibitor that targets multiple receptor tyrosine kinases, in a patient with metastatic thyroid cancer. Invest New Drugs. 2018 Apr;36(2):350-3.

6 Tohyama O, Matsui J, Kodama K, Hata-Sugi N, Kimura T, Okamoto K, et al. Antitumor activity of lenvatinib (e7080): an angiogenesis inhibitor that targets multiple receptor tyrosine kinases in preclinical human thyroid cancer models. J Thyroid Res. 2014;2014:638747.

7 Ferrara N. Vascular endothelial growth factor: basic science and clinical progress. Endocr Rev. 2004 Aug;25(4):581-611.

8 Kamba T, Tam BY, Hashizume H, Haskell A, Sennino B, Mancuso MR, et al. VEGF-dependent plasticity of fenestrated capillaries in the normal adult microvasculature. Am J Physiol Heart Circ Physiol. 2006 Feb;290(2):H560-76.

9 Nalluri SR, Chu D, Keresztes R, Zhu X, Wu S. Risk of venous thromboembolism with the angiogenesis inhibitor bevacizumab in cancer patients: a meta-analysis. JAMA. 2008 Nov;300(19):2277-85.

10 Terme M, Colussi O, Marcheteau E, Tanchot C, Tartour E, Taieb J. Modulation of immunity by antiangiogenic molecules in cancer. Clin Dev Immunol. 2012;2012:492920.

11 Katoh M. FGFR inhibitors: effects on cancer cells, tumor microenvironment and whole-body homeostasis (Review) [Review]. Int J Mol Med. 2016 Jul;38(1):3-15.

12 Qi WX, Sun YJ, Tang LN, Shen Z, Yao Y. Risk of gastrointestinal perforation in cancer patients treated with vascular endothelial growth factor receptor tyrosine kinase inhibitors: a systematic review and metaanalysis. Crit Rev Oncol Hematol. 2014 Mar;89(3):394-403.

13 Haddad RI, Schlumberger M, Wirth LJ, Sherman EJ, Shah MH, Robinson B, et al. Incidence and timing of common adverse events in Lenvatinib-treated patients from the SELECT trial and their association with survival outcomes. Endocrine. 2017 Apr;56(1):121-8.

14 Robinson B, Schlumberger M, Wirth LJ, Dutcus CE, Song J, Taylor MH, et al. Characterization of Tumor Size Changes Over Time From the Phase 3 Study of Lenvatinib in Thyroid Cancer. J Clin Endocrinol Metab. 2016 Nov;101(11):4103-9.

15 Chen LT, Chen CY, Jan CM, Wang WM, Lan TS, Hsieh MY, et al. Gastrointestinal tract involvement in hepatocellular carcinoma: clinical, radiological and endoscopic studies. Endoscopy. 1990 May;22(3):118-23. 


\section{Case Reports in Gastroenterology}

\begin{tabular}{l|l}
\hline Case Rep Gastroenterol 2020;14:63-69 \\
\hline DOI: 10.1159/000505774 & $\begin{array}{l}\text { ○ 2020 The Author(s). Published by S. Karger AG, Basel } \\
\text { www.karger.com/crg }\end{array}$ \\
\hline
\end{tabular}

Suzuki et al.: Perforation of the Small Intestine after Introduction of Lenvatinib in a Patient with Advanced Hepatocellular Carcinoma
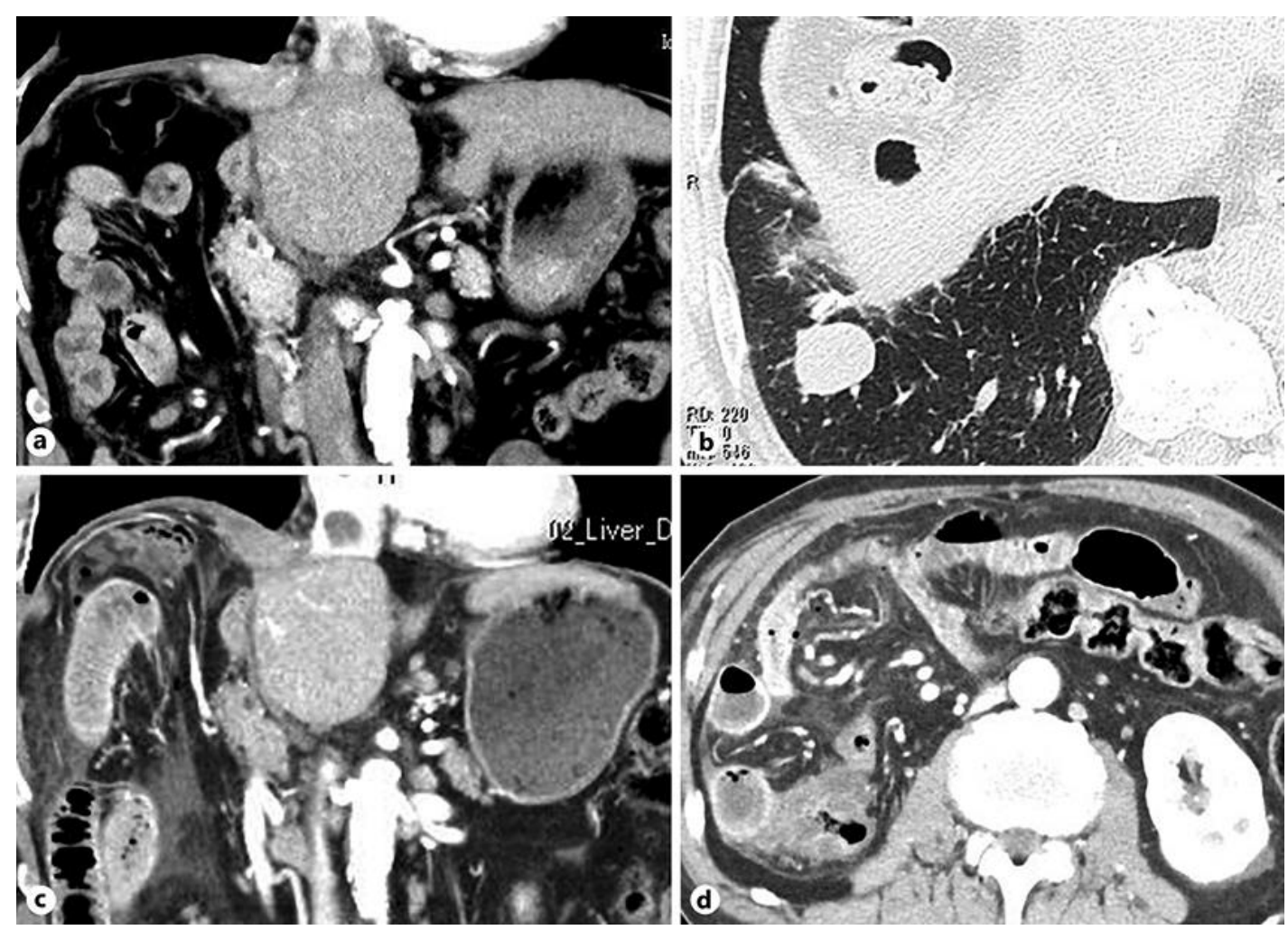

Fig. 1. CT findings at the introduction of lenvatinib. a HCC recurrence at the residual right diaphragm and caudal lobe, and a tumor thrombus extending into the inferior vena cava. b HCC metastasis in the lower lobe of the right lung. c CT findings 1 month after the introduction of lenvatinib showing free air, ascites, and a swollen small intestinal wall. Recurrent HCC at the right diaphragm and caudal lobe, and the tumor thrombus in the inferior vena cava are slightly reduced in size. $\mathbf{d}$ Retrospective examination of CT findings at the introduction of lenvatinib showing swelling of the walls of the small intestine. 


\section{Case Reports in Gastroenterology}
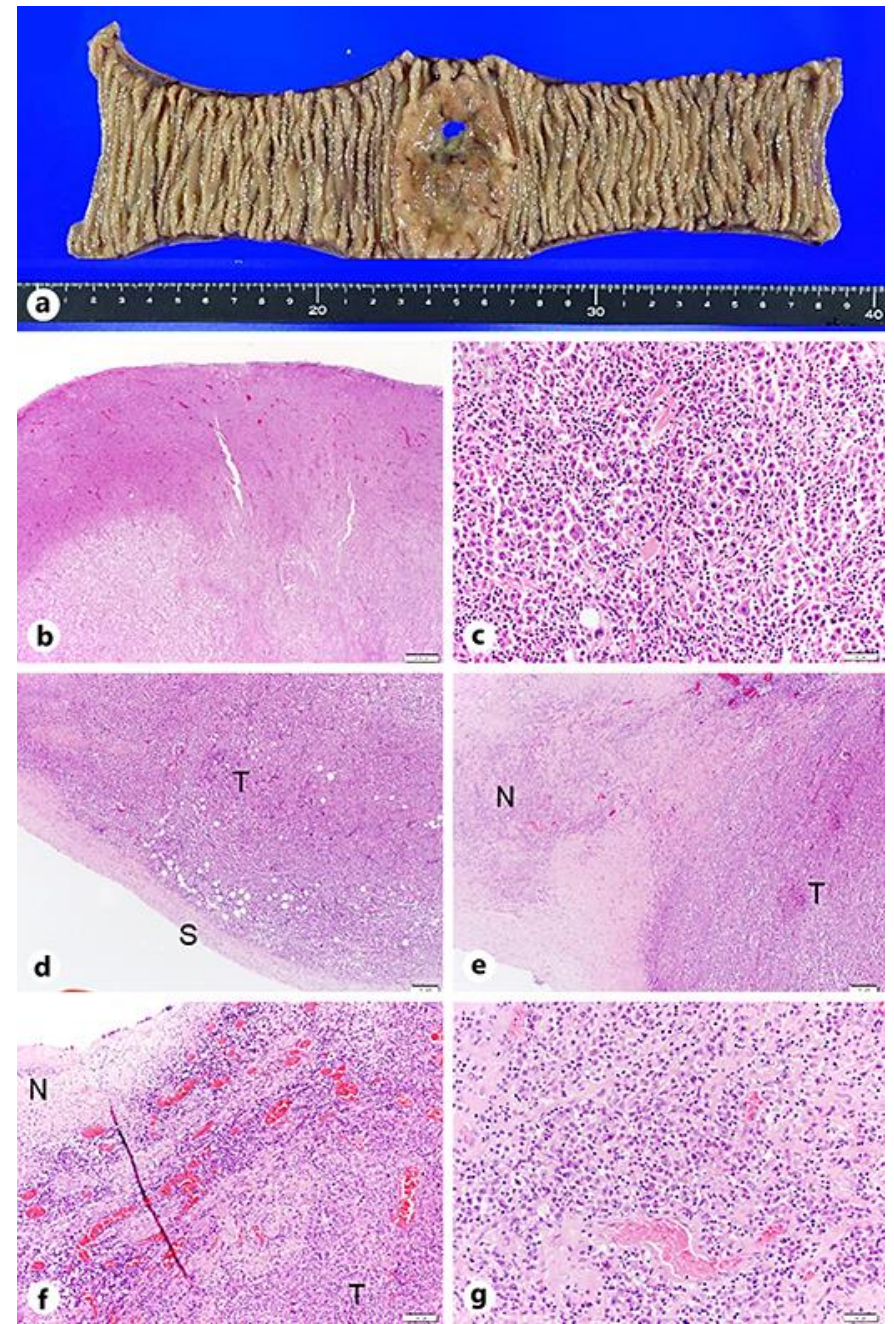

Fig. 2. a Macroscopic finding of the resected small intestine showing a protruding lesion with perforation. Necrotic changes are seen only around the perforation. $\mathbf{b}$ Findings showing poorly differentiated HCC cells throughout the entire layer of the small intestine (HE. $\times 10$ ). $\mathbf{c}-\mathbf{g}$ Histological examination. c Poorly differentiated tumor cells, similar to those in the HCC tumor resected during initial right hepatectomy (HE. $\times 400)$. $d$ Separation of the serous membrane (S) from tumor cells (T) (HE. $\times 100)$. e The site of perforation at the center of necrotic HCC, with a clear border between necrotic tissue (N) and viable tumor (T) (HE. $\times 100$ ). $f$ Small dilated tumor vessels filled with red blood cells and inflammatory cells, mainly lymphocytes, surrounding the tumor vessels at the border between the necrotic area (N) and the tumor (T) (HE. ×200). g Small vessels with fibrin clots in the necrotic areas (HE. $\times 200)$. 